\title{
Development of Phonological Processing Skills in Children With Specific Language Impairment With and Without Literacy Delay: A Three-Year Longitudinal Study
}

\begin{tabular}{|r|l|}
\hline Journal: & Journal of Speech, Language, and Hearing Research \\
\hline Manuscript ID: & JSLHR-L-10-0308.R2 \\
\hline Manuscript Type: & Research Article \\
\hline Date Submitted by the Author: & 05-Nov-2011 \\
\hline Complete List of Authors: & $\begin{array}{l}\text { Vandewalle, Ellen; Katholieke Universiteit Leuven, ExpORL, Department of } \\
\text { Neurosciences, Faculty of Medicine } \\
\text { Boets, Bart; Katholieke Universiteit Leuven, Parenting and Special } \\
\text { Education Research Group, Faculty of Psychology and Educational } \\
\text { Sciences; Katholieke Universiteit Leuven, Child Psychiatry, Department of } \\
\text { Neurosciences, Faculty of Medicine } \\
\text { Ghesquière, Pol; Katholieke Universiteit Leuven, Parenting and Special } \\
\text { Education Research Group, Faculty of Psychology and Educational Sciences } \\
\text { Zink, Inge; Katholieke Universiteit Leuven, ExpORL, Department of } \\
\text { Neurosciences, Faculty of Medicine; University Hospitals Leuven, } \\
\text { Department of ENT, Head \& Neck Surgery, MUCLA }\end{array}$ \\
\hline Keywords: & \begin{tabular}{l} 
Specific language impairment, Dyslexia, Phonology, Children \\
\hline
\end{tabular} \\
\hline
\end{tabular}


Running head: DEVELOPMENT OF PHONOLOGY IN CHILDREN WITH SLI

Development of Phonological Processing Skills in Children with Specific Language Impairment with and without Literacy Delay: A Three-Year Longitudinal Study

\author{
Ellen Vandewalle ${ }^{1}$, Bart Boets ${ }^{2,3}$, Pol Ghesquière ${ }^{2}$, Inge Zink ${ }^{1,4}$ \\ ${ }^{1}$ ExpORL, Department of Neurosciences, Faculty of Medicine, Katholieke Universiteit \\ Leuven, Belgium. \\ ${ }^{2}$ Parenting and Special Education Research Group, Faculty of Psychology and \\ Educational Sciences, Katholieke Universiteit Leuven, Belgium. \\ ${ }^{3}$ Child Psychiatry, Department of Neurosciences, Faculty of Medicine, Katholieke \\ Universiteit Leuven, Belgium. \\ ${ }^{4}$ Department of ENT, Head \& Neck Surgery, MUCLA, University Hospitals Leuven, \\ Belgium.
}

\title{
Corresponding author:
}

Ellen Vandewalle

ExpORL, Department of Neurosciences, K.U.Leuven

Herestraat 49 box 721, B-3000 Leuven, Belgium

Tel. +32(0)16330479

Fax. $+32(0) 16330486$

E-mail: ellen.vandewalle@med.kuleuven.be 
Development of Phonology in Children With SLI

\begin{abstract}
Purpose: To compare the development of phonological skills in children with SLI with and without literacy delay and to examine whether kindergarten phonological skills could discriminate these two groups.

Method: In a longitudinal study eight children with SLI and literacy delay, 10 children with SLI and normal literacy, and 14 typically developing children were studied from the last year of kindergarten to the start of grade 3. A wide range of phonological tasks (phonological awareness, PA; verbal short-term memory, vSTM; and rapid automatized naming, RAN) were administered yearly.

Results: The SLI group with literacy delay scored significantly lower than the typically developing children on almost all phonological tasks in all grades, while the SLI group with normal literacy scored significantly lower only on demanding PA and vSTM tasks. A combination of kindergarten PA and RAN skills could correctly classify $75 \%$ of the children with SLI. By including vSTM, the discriminatory value did not increase.

Conclusions: Children with SLI and normal literacy at age 8;1 years continued to have difficulties with demanding PA and vSTM tasks. Children with SLI and poor PA and RAN in kindergarten were at high risk of developing literacy problems in a transparent orthography.
\end{abstract}




\section{Introduction}

SLI is defined as an impairment of language comprehension, language production, or both, in the absence of hearing impairment, general developmental delay (i.e., a normal performance IQ), neurological impairment, and autism diagnosis (e.g., Schwartz, 2009). Children with SLI may have deficits in different oral language aspects (phonology, morphology, syntax, semantics and pragmatics). This disorder affects approximately $7 \%$ of the monolingual 5 to 6 year old children (Tomblin et al., 1997).

Dyslexia is generally defined as a disorder characterized by severe difficulties in accurate and fluent word reading and spelling that are persistent and resistant to the usual teaching measures and remedial efforts, and has a prevalence of about 5 to $10 \%$. It is widely accepted that the core deficit lies in phonological processing and stems from poorly specified phonological representations (Snowling, 2000).

SLI and dyslexia often co-occur. Data on the prevalence of the comorbidity are inconsistent, varying from $12.5 \%$ to $85 \%$ (for an overview, see McArthur, Hogen, Edwards, Heath, \& Mengler, 2000). These different estimates relate to the definitions and criteria used to diagnose SLI and dyslexia, the way of selecting participants and the age of the participants at the time of diagnosis. Because comorbidity of SLI and dyslexia is clearly above chance level, children with SLI seem to have an increased risk to develop dyslexia. The cause of this comorbidity is still under study. Different models have been proposed to explain the overlap between both disorders. Catts, Adlof, Hogan and Weismer (2005) presented three different models of the relationship between SLI and dyslexia, with a phonological processing deficit causing dyslexia. In a first one-dimensional model, SLI is a severe form of dyslexia, caused by a more severe phonological deficit. This model did not get much support because in this model all children with SLI are supposed to have literacy difficulties. In a second twodimensional model, the same phonological deficit causes SLI and dyslexia (Bishop \& 
Development of Phonology in Children With SLI

Snowling, 2004), but in SLI other nonphonological deficits cause additional problems in the development of oral language. In a third model, SLI and dyslexia are distinct developmental disorders with different cognitive deficits and different manifestations and the overlap is due to comorbidity. The data of the study by Catts et al. (2005) fitted best this model because in their study, it was observed that a deficit in phonological processing was closely associated with dyslexia but not with SLI when it occurred in the absence of dyslexia and the overlap between SLI and dyslexia was relatively small. In contrast to the previous one- and twodimensional models, a fourth model, described by Pennington (2006), takes multiple deficits into account. In this model, developmental disorders such as SLI and dyslexia are the result of multiple deficits. Comorbidity between disorders occurs because one or more of these deficits is shared. Carroll and Myers (2010) observed that both family history of dyslexia and receiving speech-language therapy were independent risk factors in predicting reading difficulties. Their results fitted most closely to this multiple deficits model of Pennington (2006). They argued that SLI and dyslexia both have shared difficulties in phonological processing combined with other disorder-specific deficits. For SLI, the disorder-specific deficits might be difficulties in semantic and syntactic aspects of language. For dyslexia on the other hand, visual-verbal association difficulties such as problems with rapid automatized naming might be a disorder-specific risk factor. SLI and dyslexia are thus separable but linked disorders. They share some risk factors and deficits, but each has additional specific deficits.

\section{Phonological Processing}

Phonological processing is used for a wide range of skills (Siegel, 2003; Uppstad \& Tonnessen, 2007). It involves the representation, manipulation, short-term storage and retrieval of speech sounds (Snowling, 2000; Wagner \& Torgesen, 1987). Three interrelated but distinctive phonological components can be distinguished: (1) phonological awareness 
(PA) or the conscious sensitivity to the sound structure of language, which is assessed by a wide variety of tasks that measure the ability to distinguish and manipulate syllables or phonemes (Yopp, 1988), such as phoneme deletion or spoonerism tasks; (2) verbal short-term memory (vSTM) or the ability to shortly maintain auditory information, usually assessed by digit span or nonword repetition tasks; (3) lexical access or the retrieval of lexical soundbased representations from long-term memory, which is measured by rapid automatized naming tasks (RAN) such as letter or colour naming. The performance on each of these three components is assumed to be determined by the quality, specificity or distinctness of underlying phonological representations (Elbro, 1996; Snowling, 2000; Wagner, Torgesen, \& Rashotte, 1994), although this remains a debated issue (Bowers \& Ishaik, 2003). There is an extensive discussion whether PA, vSTM and RAN are partially distinct cognitive skills that jointly tap a similar underlying skill called 'phonology' (Pennington, Cardoso-Martins, Green, \& Lefly, 2001; Pennington \& Lefly, 2001; Wagner et al., 1994) or whether RAN has an independent status.

Within the phonological awareness component, tasks may encompass different subskills that may be linked in different ways to the acquisition of reading and spelling skills (Treiman \& Zukowski, 1996). The use of such a wide variety of tasks makes interpretation, consolidation and comparison of research findings difficult (Yopp, 1988). Performance varies with the cognitive demands of the task. Complex tasks, which require more steps to completion and which place a greater burden on memory, tend to be harder than simple tasks. Performance also depends on the linguistic level that is tapped by the task. This linguistic level is determined by the size of the shared unit (Brady, Fowler, Stone, \& Winbury, 1994; Walley, Smith, \& Jusczyck, 1986). For example, syllables are more accessible than rimes/onsets and rimes/onsets are more accessible than phonemes. However, also the linguistic status of the unit determines the difficulty level (Treiman \& Zukowski, 1996). It is 
Development of Phonology in Children With SLI

for instance easier to detect a shared consonant when it constitutes an individual onset than when this consonant is part of a cluster onset. There exists controversy whether the different levels of phonological awareness represent one general ability or several distinct abilities. Based on the results of four independent studies, Anthony and Lonigan (2004) concluded that sensitivity to these various linguistic units can be best conceptualized by one general underlying phonological ability.

\section{The Link Between Phonological Processing and Reading Development}

Several prospective longitudinal studies have suggested a causal and reciprocal link between sensitivity to the phonological structure of words and progress in reading acquisition (e.g., Bentin \& Leshem, 1993; Wagner et al., 1994). It is generally accepted that PA and RAN are good predictors for reading in typically developing children (for a review, see Scarborough, 1998). This relationship between phonological abilities and reading achievement also depends on the level of reading proficiency and the phase of reading acquisition (de Jong \& van der Leij, 1999). In general, PA tends to be more important in the initial phases of reading development and is more strongly related to reading accuracy. RAN is of greater importance in the later development of reading fluency and reading comprehension and relates more to reading speed (e.g., van den Bos, Ruijssenaars, \& Spelberg, 2008; Verhagen, Aarnoutse, \& van Leeuwe, 2008). Individual differences in nonalphanumeric RAN, PA, and letter knowledge measured before reading instruction, are strong, independent predictors of subsequent reading achievement (Lerväg \& Hulme, 2009). After the onset of reading instruction, alphanumeric RAN predicts further reading development better than non-alphanumeric RAN (Lerväg \& Hulme, 2009).

In children with dyslexia, persistent deficits have been shown in PA, vSTM and RAN (e.g., Boets et al., 2010). In the double deficit hypothesis, RAN is considered as a unique and 
independent predictor for dyslexia besides the PA deficit (e.g., Bowers \& Ishaik, 2003; Wolf \& Bowers, 1999). This hypothesis predicts that if both PA and RAN skills are affected, the child has a double deficit and his or her reading and spelling impairment will be more severe. Although it is not clear whether similar impairments predict reading and spelling problems in children with SLI, a number of SLI studies did retain the same predictors, such as PA and RAN (Catts, Gillispie, Leonard, Kail, \& Miller, 2002; Elbro \& Scarborough, 2004; Scarborough, 1998).

Differences in languages, and especially differences in the transparency of the orthography, can influence the rate and pattern of development of phonological processing and literacy skills. Both oral and written language input play a role in raising children's phonological awareness. In a language with a relatively transparent orthography, metaphonological abilities (i.e., PA) tend to develop more quickly than in languages with less transparent orthographies (Caravolas \& Bruck, 1993). Moreover, RAN skills assessed in kindergarten might be a more important predictor for reading development than PA and vSTM, especially for the development of reading fluency which is the main deficit in dyslexic children in a transparent language (de Jong \& van der Leij, 1999; Wimmer, Mayringer, \& Landerl, 2000). Brizzolara et al. (2006) suggested that impairments in RAN may represent the main cognitive marker of developmental dyslexia in a transparent language.

\section{Development of Phonological Processing in Children with SLI}

The developmental trajectories of the different phonological components have rarely been reported in children with SLI. In the following we present an overview of cross-sectional and longitudinal studies dealing with the development of phonological processing in children with SLI. 
Development of Phonology in Children With SLI

\section{Phonological awareness.}

Treiman and Zukowski (1996) mentioned that different aspects of PA develop at different phases. In typical development, children initially learn to segment speech into words. This is followed by the ability to divide words into syllables. Then they gain the aptitude to divide syllables into intra-syllabic components, and finally intra-syllabic units into phonemes. The developmental trend that segmentation at syllable level is easier than segmentation at intra-syllabic level which on its turn is easier than segmentation at phoneme level was observed in a cross-sectional study of Thatcher (2010) in 15 typically developing children. However, this trend could not be confirmed in 15 children with SLI from preschool ( $4 ; 7$ years), over kindergarten $(6 ; 1$ years) to first grade $(7 ; 5$ years). The children with SLI exhibited no significant improvement in their abilities to segment at the various levels. This might be explained by generally decreased PA abilities in children with SLI. In contrast to the PA development in phases in typically developing children, several studies did not find a staged progression of PA from syllables to rimes to phonemes to be universal. Children can detect similar- and dissimilar-sounding words before they can manipulate sounds within the words, and children can generally blend phonological information before they can segment phonological information of the same linguistic complexity (Anthony, Lonigan, Driscoll, Phillips, \& Burgess, 2003). Moreover, children refine phonological awareness skills they have already acquired while they are learning new phonological awareness skills (Anthony et al., 2003), contrary to a strict stage theory of development. Moreover, there are a number of oral and written language effects playing a role on the development of PA (for an overview, see Anthony and Francis, 2005). A more specific study for Dutch language by Geudens and Sandra (2003) revealed the important role of phonetic factors in the segmentation of syllables (e.g., segmenting VC-syllables was easier for prereaders and first grade readers than segmenting CV-syllables). 
Early PA deficits are present in young children with SLI with and without later dyslexia (i.e., at 4 and 6 years old and in grade 2) (Bishop, McDonald, Bird, \& HayiouThomas, 2009; Catts, Adlof, Hogan, \& Weismer, 2005), but they resolve over time (i.e., in grade 4 and 8) in those children who develop normal reading skills (Catts et al., 2005). Whereas Bishop et al. (2009) suggested that PA is related to oral language development, Catts et al. (2005) concluded that PA processing is specifically related to reading development. Catts et al. suggested that this time-effect may either reflect the reciprocal relation of reading and PA or it may indicate that PA deficits are more stable over time in children with dyslexia.

\section{Verbal short-term memory.}

Children with SLI frequently experience vSTM problems, especially problems with nonword repetition, and these problems seem to be persistent (Conti-Ramsden \& Durkin, 2007). Nonword repetition skills have been claimed to be a reliable marker of SLI (Gathercole, Willis, Baddeley, \& Emslie, 1994). These skills are impaired in 4 to 6 year old children with SLI with and without later dyslexia (Bishop et al., 2009; de Bree, Wijnen, \& Gerrits, 2010), but they improve in children with SLI and normal literacy in grade 2 or later (Bishop et al., 2009; Catts et al., 2005; Rispens \& Parriger, 2010). In kindergarten, vSTM seems to be more related to oral language ability. However, after 6 years of age, vSTM may be more related to literacy development than to oral language development (Catts et al., 2005; Rispens \& Parriger, 2010) and hence, the nonword repetition test may no longer be a valid marker for SLI in general after 6 years of age. It is still debated whether the vSTM problems of individuals with SLI do resolve in later grades. In the studies of Rispens and Parriger (2010) and Bishop et al. (2009), no significant differences in vSTM were observed between the normal reading SLI group and typically developing children at respectively $8 ; 3$ and $9 ; 0$ years. However, other studies suggest that children with SLI and normal literacy might still show mild vSTM problems (Catts et al., 2005), even until 11 years of age (Conti-Ramsden \& 
Development of Phonology in Children With SLI

Durkin, 2007). It remains unclear whether the observed differences in nonword repetition skill between the SLI groups with and without literacy impairment are a consequence or a precursor of differences in literacy ability. In most abovementioned studies, group differences were explained as a consequence of differences in reading ability, although this unidirectional influence was only proven by Conti-Ramsden and Durkin (2007) and Nation and Hulme (2011). Moreover, in this last study, nonword repetition was not a longitudinal predictor of the growth in reading.

\section{Rapid automatized naming.}

RAN skills seem to correlate with reading and not with oral language ability (Bishop et al., 2009; Brizzolara et al., 2006). Indeed, Bishop et al. (2009) observed that RAN skills measured at 9 years were impaired in children with SLI and literacy problems, but were equivalent to typically developing children in children with SLI and normal literacy. In line with these findings, Brizzolara et al. (2006) observed that RAN deficits were present in most individuals with dyslexia, not merely in those with a history of language impairment. Moreover, RAN measured at 9 years was the strongest predictor to differentiate a group of children with SLI in a group with and a group without dyslexia (Bishop et al., 2009).

\section{Present Study}

There is a lack of longitudinal studies examining all three phonological components (i.e., PA, VSTM and RAN) in children with SLI with and without literacy delay and typically developing controls at multiple time points before and after the start of formal reading instruction. Developmental trajectories of the different phonological components have rarely been reported for children with SLI. The present study examined phonological processing in children with SLI with and without literacy problems and matched controls from the last year of kindergarten until the start of grade 3. Children in this study spoke Dutch, a language with 
a relatively transparent orthography. A first account of this study (Vandewalle, Boets, Ghesquière, \& Zink, 2010) was restricted to phonological data in kindergarten and literacy skills in grade 1. Here, it was observed that in kindergarten, children with SLI showed impairments in PA and vSTM but not in RAN. Only children with SLI and literacy delay at the end of grade 1 scored poorer on RAN in kindergarten. RAN in kindergarten was highly correlated to literacy skills at the end of grade 1 and therefore RAN seemed to be a good predictor for literacy skills in children with SLI. In the present study, participant groups were defined by combining literacy status in first and third grade (literacy delayed versus normal literacy ability) with the clinical status of SLI. The study comprised three groups: (1) children with SLI and literacy delay, (2) children with SLI and normal literacy, and (3) typically developing control children. We aimed to investigate in which phonological skills (PA, vSTM and RAN) the three groups of children differed over the three-year period from kindergarten to third grade and how the different phonological skills developed over this period. Moreover, we wanted to examine whether phonological skills measured in kindergarten could discriminate the children with SLI in a group with and a group without high risk for developing literacy problems.

\section{Method}

\section{Participants}

Eighteen children (three girls and 15 boys) with a formal SLI diagnosis participated in the study. All children were born in 2000, attended the last year of regular kindergarten at the start of the study, were monolingual Dutch speakers, and had severe and persistent oral language problems for which they already received oral language therapy in kindergarten. Oral language problems were determined by a score below percentile 3 before the start of language therapy on at least one of the subtests of three standardized Dutch language tests: 
Development of Phonology in Children With SLI

Reynell Taalontwikkelingsschalen [Reynell Language Developmental Scales] (Schaerlaekens, Zink, \& van Ommeslaeghe, 2003), Taaltests voor Kinderen [Language Tests for Children] (van Bon \& Hoekstra, 1982a) or Schlichting Test voor Taalproductie [Schlichting Test for Language Production] (Schlichting, van Eldik, Spelberg, van der Meulen, \& van der Meulen, 2003). At a second evaluation after the age of 4;4 years, they all had to score below percentile 10 on at least one of the subtests of these language tests to ensure the persistency of the language problems. In addition to these language problems, some children had concurrent articulation problems. Exclusion criteria were low intelligence (non-verbal, verbal and total IQ below 85), hearing loss or any other known problem (e.g., neurological disorder) that could explain their language impairment.

For every individual child of the SLI group, the best matching control child was selected based on five criteria: (1) educational environment (i.e., same class), (2) gender, (3) age, (4) non-verbal intelligence, and (5) parental educational level. We followed an elimination procedure to detect the best matching child. Firstly, parents of all children from the same class and the same gender as the child with SLI were requested to grant parental consent and to complete a questionnaire. Secondly, all bilingual children and all children with speech, language or hearing difficulties mentioned by the teacher or parents were omitted. Thirdly, non-verbal intelligence was assessed with the Raven Coloured Progressive Matrices (Raven, Court, \& Raven, 1984). Based on age, non-verbal intelligence and parental educational level (International Standard Classification of Education scale; UNESCO, 1997) and in this order of importance, the best matching control child was selected.

Although initially 26 children with SLI were selected, only 18 are included in the present report because one child left the study after kindergarten and seven children did not move on to grade 1 of a regular primary school after the last year of kindergarten. Hence, only 
the data of the 18 children with SLI and their 18 matched controls attending regular primary school were further analyzed in this study.

Both the SLI group and the control group were divided into two subgroups based on word reading and spelling achievement in first and third grade. In Flanders, children start literacy instruction at school in grade 1 at the age of 6 . All children scoring $1 S D$ below the mean of a normative reference group on a standardized word reading (van den Bos, Spelberg, Scheepstra, \& De Vries, 1994) and/or spelling test (Dudal, 2006a), in both first and third grade were classified as 'literacy delayed'. This criterion took into account both the severity and the persistence of a child's literacy problem. By applying this criterion, we identified eight children with literacy delay in the SLI group and four children in the control group. In the following analyses only three groups of children are compared: (1) children with SLI and literacy delay (SLI-LD; $n=8$ ), (2) children with SLI and normal literacy (SLI-NL; $n=10$ ), and (3) control children with normal literacy (Control-NL; $n=14$ ).

Descriptive statistics and Mixed Model Analyses (MMA) of word reading and spelling skills at the end of grade 1 and at the beginning of grade 3 are presented in Table 1. As defined, the SLI-LD group scored lower than the SLI-NL group and the Control-NL group on word reading and spelling with large effect sizes. However, these group differences were not always significant, especially for word reading. MMA group comparisons for age and nonverbal intelligence showed that the three groups had equivalent age $(F(1,29)=0.10$; $p=.90)$ and did not differ significantly on non-verbal intelligence $(F(2,29)=2.67 ; p=.09)$ (see Table 1). In contrast, a Fisher's Exact Test revealed significant group differences for educational level of the mother ( $p=.03$; Fisher's Exact Test). In the SLI-LD group, three mothers had a low, four a middle and one a high educational level. In contrast, the SLI-NL group counted zero mothers with low, seven with middle and three with high educational level. The Control-NL group counted respectively one, four and nine mothers with low, 
middle and high educational level. Because of these differences, maternal educational level was controlled for in all group comparisons.

[Insert Table 1]

\section{Measures}

Phonological abilities.

A number of PA and RAN tests used in this study were similar to the phonological awareness and naming speed tests of the Phonological Assessment Battery (PhAB;

Frederickson, Frith, \& Reason, 1997; Wheldall \& Pogorzelski, 2003). For each of the

experimental non-standardized tests, Cronbach's alpha was calculated and added as a measure of internal consistency (see Table 2).

\section{Phonological awareness (PA).}

The phonological awareness test battery was based on previous research (Boets et al., 2010; Boets, Wouters, van Wieringen, \& Ghesquière, 2006; de Jong, Seveke, \& van Veen, 2000) and consisted of a series of tasks that were designed to meet the rapidly changing level of phonological performance in children starting to read and write. Each task was preceded by two practice items to familiarize children with the task requirements. For each correct answer, one point was assigned.

Rime production task. In this task, a one-syllable word and an exemplary riming word were given and the child had to produce another riming word or nonword. The test consisted of eight items gradually getting more difficult.

Identity tasks. Three identity tasks were administered. In the end rime identity task a picture of a one-syllable consonant-vowel-consonant (CVC) or CVCC word was shown and named to the child, and the child had to select from four alternatives (named and shown on a picture) the word that had the same end rime as the given word. The total number of items 
was 12 . The same format was used for the first sound identity task and the end sound identity task, where the child had to select from four alternatives the word that respectively started or ended with the same sound (a single consonant) as a given word. The total number of items on each test was 10 .

Categorization tasks. In the first sound categorization and the rime categorization task each item consisted of three monosyllabic words presented twice from a CD with an interstimulus interval of one second. The child was asked to name the two words that had the same first sound or the same end rime, respectively. The first sound categorization task had 15 items. Eight items consisted of words that started with a single consonant; seven items involved words that began with a consonant cluster. The rime categorization task consisted of 20 items of varying difficulty level (by using diphthongs or by manipulating the phonological similarity with the distracter item).

Auditory analysis and synthesis. The auditory analysis and synthesis task were part of a standardized Dutch test battery to measure phonology and reading (Drie-Minuten-Toets; Verhoeven, 1995). In the analysis task, the child had to analyze a word into phonemes. In the synthesis task, the child had to aggregate the individual phonemes (presented auditory on a $\mathrm{CD}$ with an interval of one second between the phonemes) to reconstruct the word. For both tasks, the one-syllable words of the 20 items increased in length and difficulty level, with more consonant clusters in the items at the end of the task.

Phoneme deletion. The phoneme deletion task consisted of 28 one-syllable nonwords that were presented twice from a CD (an adaptation of de Jong \& van der Leij, 2003). The child was asked to delete a given phoneme of the nonword. In all items, the first or second consonant of a consonant cluster in the start or end position had to be deleted (e.g., BIJLF without /f/ becomes BIJL). For the first 10 items, the deletion of the phoneme resulted in an existing word. For the next 18 items, the residual phonological string remained meaningless 
after phoneme deletion. The maximum score on the test was 28 . In grade 1 , the task was terminated after 20 items because of the high complexity of the last items.

Spoonerism. The spoonerism task consisted of three sets of 10 items. For all sets, the first five items resulted in the disclosure of existing words, and the remaining five items yielded nonwords. In the first set, the child was required to replace the onset (consonant or consonant cluster) of a word with another consonant (cluster) in order to create a new word or nonword (e.g., KAT with $/ \mathrm{m} /$ becomes MAT). In the second and third set, two one-syllable words were given and the child was instructed to swap their consonant onset in order to produce two new words or nonwords (e.g., MUS-KAT becomes KUS-MAT ). In the second set, words started with a single consonant; in the third set, words started with a consonant cluster. Each correctly produced word and nonword was rewarded with one point, with a maximum score of 50 on the whole test. Every child completed all items of the first set. The second and third sets were discontinued after four consecutive errors ( $0 / 2$ for an item). The third set was only presented to those children who obtained a score equal to or above $6 / 20$ on the second set.

\section{Verbal short-term memory (vSTM).}

Verbal short-term memory was assessed by a digit span forward task and a nonword repetition task (Boets et al., 2006).

Digit span forward. In this task, the child had to correctly recall a sequence of digits presented from a CD. Testing started with a sequence of two digits. After presenting three trials of the same list length, the sequence was increased by one digit. The test ended after three consecutive errors. The test score was the total number of correctly recalled lists.

Nonword repetition. In this task (adapted version of Gathercole et al., 1994), as described in Boets et al. (2006), the child had to repeat a nonword presented from a CD. The difficulty level of the 48 nonwords increased gradually from two to five syllables, with half of 
the items in each category containing consonant clusters in different medial positions. Only completely correctly repeated nonwords were rewarded with one point.

\section{Rapid automatized naming (RAN).}

Lexical access was evaluated with four classic rapid automatized naming tasks, which involved the naming of highly familiar colours, objects, digits and letters (van den Bos, Zijlstra, \& Spelberg, 2002). Each task involved the presentation of a card of five different stimuli randomly arranged in five columns of 10 stimuli, with each stimulus appearing 10 times. The participant was instructed to serially name the stimuli on the card as quickly and accurately as possible. The time to complete the card was recorded for each task. Colour naming comprised the colours black, blue, red, yellow and green, which were represented by small rectangles. Object naming involved the naming of five high-frequent, one-syllable words: boom ('tree'), eend ('duck'), stoel ('chair'), schaar ('scissors') and fiets ('bicycle'). Digit naming involved the digits 2, 4, 8, 5 and 9. Letter naming involved the naming of the lowercase letters d, o, a, s and p. The RAN-score was calculated as the number of symbols named per second.

\section{Literacy skills.}

Reading.

The One-Minute Reading test (van den Bos et al., 1994) was administered both in grade 1 and grade 3 as a standardized measure of single word identification. This test combined speed and accuracy into one index score. The child had to read a list of words of increasing difficulty (with increasing number of syllables and consonant clusters) as correctly and quickly as possible. The score on the test was the number of words read correctly within one minute. For diagnostic purposes, this score was transformed to an age-adjusted standard score relative to population average. 
Development of Phonology in Children With SLI

\section{Spelling.}

Spelling was evaluated by a standardized spelling achievement test (Dudal, 2006a).

Grade-appropriate versions of the test were used in first and third grade measuring spelling features increasing in difficulty level. In grade 1, children had to spell single words presented in isolation, single words presented in sentence context, and short sentences. The maximum score on the test was 60 . In grade 3, children had to spell words in sentences with a maximum score of 30. For diagnostic purposes this score was transformed to an age-adjusted standard score relative to population average.

\section{Design and Procedure}

The administration of the tests was spread over a period of three years. Phonological skills were measured at three time points, that is in the middle of the last year of kindergarten (mean age $=5 ; 7$ years), in the middle of grade 1 (mean age $=6 ; 7$ years) and at the beginning of grade 3 (mean age $=8 ; 1$ years). In kindergarten, four PA tasks were administered, that is rime production, end rime identity, first sound identity and end sound identity. In grade 1, children performed six more difficult PA tasks, that is rime and first sound categorization, auditory analysis and synthesis, phoneme deletion and spoonerism. In grade 3, the children performed the same phoneme deletion and spoonerism task again. To measure vSTM, the digit span and nonword repetition task were administered at the three time points. RAN was assessed with the colour and object naming tasks in kindergarten. In grade 1 and grade 3 , the RAN tasks comprised colour, object, digit and letter naming. Literacy skills were measured after one year of literacy instruction at the end of grade 1 (mean age $=6 ; 10$ years) and after two years of literacy instruction at the beginning of grade 3 (mean age $=8 ; 1$ years) by the same word reading test and a grade-appropriate version of the spelling test. Each matched pair of children from the SLI and control group was tested in a quiet room at their school under 
identical circumstances and when feasible on the same day. All tests were administered individually, only the tests for non-verbal intelligence and spelling were administered individually in small groups. Data collection was carried out by trained students in speechlanguage therapy.

Groups were compared using MMA with pair as a random variable and participant group (SLI-LD, SLI-NL and Control-NL) as the fixed between-subject variable. Maternal educational level was included as fixed covariate. To investigate developmental trends, repeated measures MMA were calculated with time (kindergarten, grade 1 and grade 2) as within-subject variable, participant group (SLI-LD, SLI-NL and Control-NL) as betweensubjects variable and with maternal educational level as covariate. Post hoc analyses were corrected for multiple comparisons using the Tukey procedure, and standardized mean differences were calculated as a measure of effect size by dividing the difference between the least-squares means by the pooled standard deviation. As described by Welkowitz, Ewen and Cohen (1988), an effect size of 0.2 was considered as small, whereas an effect size of 0.5 was called medium and an effect size of 0.8 is called large. Given the rather small sample sizes, it should be noted that the statistical power to discern significant group differences was relatively small. Often, there were large and potentially meaningful effect sizes with a large power, but these did not reach significance. Therefore, we also analyzed the effect sizes for the interpretation of the results.

Variables that were assumed to measure a common theoretical construct were aggregated into composite scores in order to give a quick overview of developmental trends. Based on a series of principal component analyses in previous research (Boets et al., 2010), we could conclude that the phonological battery indeed represented the well-known threedimensional phonological structure. Composite scores for PA, vSTM and RAN were calculated by computing $z$-scores for each task (relative to the mean and standard deviation of 
Development of Phonology in Children With SLI

the Control-NL group) and averaging the scores of the tests that constituted the same underlying construct. All composite scores at all time-points were further standardized relative to the mean and standard deviation of the Control-NL group. In this manner, the Control-NL group had a mean of 0 and $S D$ of 1 at each time point.

Predictive discriminant analyses were used to determine how well the phonological measures discriminated between the children with SLI and literacy delay and the children with SLI and normal literacy (cf., Bedore \& Leonard, 1998; Plante \& Vance, 1994).

Discriminant analyses and cross validation were applied to the three kindergarten composite scores. Discriminant analysis generates a discriminant criterion that maximizes the distance between the groups. Cross validation uses the discriminant criterion to assess the error rate for the discriminant function by comparing each observation to the remaining data set and calculating the probability that it belongs to either of the groups.

\section{Results}

We analyzed the development of the phonological skills (PA, vSTM and RAN) for the three groups (SLI-LD, SLI-NL and Control-NL group) over the three-year period from kindergarten to third grade. Descriptive statistics and MMA group comparisons are presented in Table 2.

The composite scores for $P A$ at the three time points revealed a significantly lower score for the SLI-LD group compared to the Control-NL group with large effect sizes. When comparing the composite scores for the SLI-NL group with the two other groups, we observed that the SLI-NL group scored in between the SLI-LD and the Control-NL group. There was a large and significant group difference between the SLI-NL and Control-NL group for the PA composite scores, except in kindergarten. Comparisons between the SLI-NL and SLI-LD groups revealed medium to large but no significant effect sizes. At the level of 
the individual PA tasks, the SLI-NL group scored either similar to the SLI-LD group or scored in between the SLI-LD group and the Control-NL group. It is notable that the standard deviation for most PA tasks in kindergarten was much larger for both SLI groups in comparison with the Control-NL group. To investigate developmental trends, repeated measures mixed models were calculated for each task that was assessed at multiple time points. The three groups made comparable development from grade 1 to grade 3 for the phoneme deletion and spoonerism task. There was a main effect of group (for the two tasks, respectively $F(2,27)=12.60 ; p=.0001$ and $F(2,27)=8.89 ; p=.001)$ and a main effect of time (respectively $F(1,29)=62.70 ; p<.0001$ and $F(1,29)=45.60 ; p<.0001$ ), but no significant group by time interaction (respectively $F(2,29)=1.36 ; p=.27$ and $F(2,29)=0.46$; $p=.63)$.

[Insert Table 2]

At every time point, the composite scores for $v S T M$ revealed significantly lower scores for both SLI groups compared to the Control-NL group, whereas there was neither significant group difference nor a substantial effect size between both SLI groups. It is evident that nonword repetition is much more sensitive to differentiate the SLI groups from the ControlNL group than digit span. Nonword repetition was consistently and significantly impaired in both SLI groups. For digit span, the group difference was smaller and not always significant, although effect sizes revealed a similar pattern. Considering the development of vSTM, the three groups made comparable progress from kindergarten to grade 3. For digit span and nonword repetition there was a main effect of group (respectively $F(2,27)=3.35 ; p=.05$ and $F(2,27)=15.55 ; p=<.0001)$ and a main effect of time (respectively $F(2,58)=60.60 ;$ $p<.0001$ and $F(2,58)=61.11 ; p<.0001)$, but no significant group by time interaction $($ respectively $F(4,58)=1.63 ; p=.18$ and $F(4,58)=2.13 ; p=.09)$. 
Development of Phonology in Children With SLI

In kindergarten, $R A N$ scores differentiated between the SLI-LD group and the ControlNL group and also between the two SLI groups. Although the effect sizes were substantial, the group difference was only significant on the colour naming task between the SLI-LD group and the Control-NL group. Effect sizes of the group comparisons were smaller in grade 1. In grade 3, there was a substantial difference between children of the SLI-LD group and the Control-NL group with large effect sizes, in particular for the colour naming task. On the other RAN tasks, the group difference did not reach significance level. Repeated measures MMA only showed a main effect of group $(F(2,27)=3.28 ; p=.05)$ on the RAN colour naming task. For all RAN tasks there was a main effect of time (RAN colours: $F(2,58)=$ 79.69; $p<.0001 ;$ RAN objects: $\mathrm{F}(2,58)=79.75 ; p<.0001 ;$ RAN digits: $\mathrm{F}(1,29)=142.36 ; p<$ .0001 ; RAN letters: $\mathrm{F}(1,29)=33.65 ; p<.0001)$. The group by time interaction was only significant for the RAN letter naming task $(F(2,29)=4.62 ; p=.02)$.

We can summarize that for all phonological abilities children of the three groups made significant progress from kindergarten to grade 3 . The rate of development was similar across the groups for PA and vSTM. For RAN, however, the Control-NL group made more progress on the RAN letter naming task compared to the two SLI groups. Group comparisons revealed that for PA, in general, the SLI-LD group scored significantly lower than the Control-NL group. The SLI-NL group scored in between the SLI-LD and Control-NL group (i.e., somewhat better than the SLI-LD group and in half of the tests significantly poorer than the Control-NL group). For vSTM, both SLI groups did not differ from each other and scored lower than the Control-NL group. For RAN, the SLI-LD group scored somewhat lower than the SLI-NL group and substantially lower than the Control-NL group in kindergarten.

Predictive discriminant analyses were calculated to analyze the predictive value of each of the three kindergarten phonological components for distinguishing between children with SLI that would develop normal versus delayed literacy skills. The percentage and actual 
number of cases that were correctly classified in the cross-validation analyses are summarized in Table 3. A combination of the three phonological composite scores PA, vSTM and RAN resulted in a sensitivity of $75 \%$ for the SLI group with literacy delay (6 of the 8 children with literacy delay were detected) and a specificity of $80 \%$ for the SLI group with normal literacy ( 8 of the 10 children without literacy delay were correctly classified). A combination of the PA and RAN composite variables produced the same classification results. Hence, vSTM did not bring any additional discriminatory value. When only PA or only RAN was used, similar specificity but lower sensitivity was observed. VSTM as a single classification variable had a very low sensitivity and specificity. Interestingly, when implementing discriminant analyses on single tests instead of composite variables, a well-selected combination of one kindergarten PA variable (end rime identity task) and one kindergarten RAN variable (RAN test for objects) could achieve the same results as the combination of the PA and RAN composite variables.

[Insert Table 3]

\section{Discussion}

Based on this three-year longitudinal study of phonological processing in children with SLI and literacy delay, children with SLI and normal literacy and typically developing children, several conclusions about the development of PA, vSTM and RAN and their predictive value for literacy delay could be drawn.

First, our results suggested that children with SLI and literacy delay showed extensive and persistent PA problems, at least until grade 3. On almost every PA task across the three time points, the SLI-LD group scored significantly poorer than the Control-NL group. In comparison, children with SLI and normal literacy showed milder PA problems, at least until grade 3 . They mainly struggled with higher-order linguistic, more demanding or less familiar 
Development of Phonology in Children With SLI

PA tasks. On easier tasks (i.e., lower linguistic level and more familiar tasks), like riming in the last year of kindergarten (Stanovich, 1988; Yopp, 1988) and first sound categorization in grade 1, children with SLI and normal literacy obtained scores close to those of typically developing children. On more demanding tasks (i.e., more difficult, higher linguistic level and less familiar tasks), both SLI groups had difficulties compared to typically developing children. In the last year of kindergarten, a task at phoneme level was very difficult and not often trained. On the first sound identity task, for instance, the two SLI groups scored significantly lower in kindergarten compared to the control group. In grade 1, phoneme deletion (see also Stanovich, 1988; Yopp, 1988) and spoonerism were difficult and unfamiliar tasks. Accordingly, the two SLI groups scored significantly lower on these tasks than the control group, while there was no significant difference between both SLI groups. In grade 3, the phoneme deletion task became somewhat less demanding (see also Durgunoglu \& Öney, 1999) and at this moment, the SLI-NL group did no longer differ significantly from the Control-NL group. In contrast, the spoonerism task was still difficult in grade 3 as was reflected in the lower scores for both SLI groups in comparison with the Control-NL group. Additionally, for some tasks there might have been a ceiling effect for the Control-NL and SLI-NL group, prohibiting these groups to obtain higher scores. This phenomenon was potentially apparent in the rime production and end rime identity task in kindergarten. This might have been the reason for the absence of significant group differences for these tasks between the SLI-LD group and the two other groups.

The observation that in kindergarten both the children with SLI with and without later literacy delay had PA problems confirmed our previous findings (Vandewalle et al., 2010) and kindergarten data of larger studies (Bishop et al., 2009; Catts et al., 2005). In the study by Catts et al. (2005) PA skills (measured by a phoneme deletion task) improved in grade 4 and grade 8 in children with SLI and normal reading. This was in accordance with our observation 
that for phoneme deletion children with SLI and normal literacy did not anymore score significantly lower than the Control-NL group in grade 3 . We could support the conclusion of Catts et al. (2005) that PA deficits in later grades were more related to dyslexia than to SLI: PA deficits seemed to be more stable over time across all PA tasks in children with literacy delay.

The observation that children with SLI and normal literacy skills showed remaining PA problems with more demanding PA tasks in the first three grades of primary school suggested that they still seemed to be at risk for developing literacy problems. Therefore, the risk for dyslexia in children with SLI seemed to be continuous rather than discrete, comparable to the family risk for dyslexia (Boets et al., 2010; Pennington \& Lefly, 2001; Snowling, Gallagher, \& Frith, 2003).

Landerl and Wimmer (2000) warned that some PA tasks, such as spoonerism, place a large burden on working memory skills, and thus were not a pure measure of PA. Because children with SLI typically have persistent working memory problems (Conti-Ramsden \& Durkin, 2007), this could be an alternative explanation for the PA problems in children with SLI. Indeed, for spoonerism all children with SLI had significantly more problems in comparison to typically developing children. However, this alternative explanation did not hold for all our results. We also measured other PA tasks requiring working memory skills, such as rime and first sound categorization in grade 1 , in which the children had to remember three words and then had to decide whether the words rimed or had the same first sound. Yet, in spite of the heavy working memory load, children with SLI and normal literacy did not fail on these tasks.

Second, with regard to vSTM, we could infer that vSTM problems, as measured by more demanding tasks such as nonword repetition, seemed to persist in all children with SLI, at least until grade 3. Both the SLI group with normal and delayed literacy achievement 
Development of Phonology in Children With SLI

scored significantly lower than controls on nonword repetition from kindergarten until grade 3. Furthermore, both SLI groups did not differ significantly from each other. Persistent vSTM problems in children with SLI were also observed by Conti-Ramsden and Durkin (2007). Moreover, the lack of significant differences between both SLI groups corroborated the findings of Bishop et al. (2009) and de Bree et al. (2010), in four-year-old and six-year-old children, respectively, but was in contrast with studies at older ages (Bishop et al., 2009; Catts et al., 2005; Rispens \& Parriger, 2010). Our observation that children with SLI and normal literacy still scored significantly lower for nonword repetition than the typically developing group until grade 3, was in accordance with the study of Catts et al. (2005), but contradicted the studies of Rispens and Parriger (2010) and Bishop et al. (2009). Thus, at least until grade 3 , our results did not support the suggestion that nonword repetition problems disappeared in children with SLI and normal literacy. In addition to the age of the children, the difficulty of the nonword repetition task, as determined by the syllable length (Dollaghan \& Campbell, 1998), the number of items with consonant clusters (Rispens \& Parriger, 2010) and the position of the consonant cluster (Marshall \& van der Lely, 2009) could be a differentiating factor between the results of the studies. In the studies of Bishop et al. (2009), Conti-Ramsden and Durkin (2007) and in our study, half of the items contained consonant clusters (see Gathercole et al., 1994). In contrast, the items in the studies of Catts et al. (2005), de Bree et al. (2010) and Rispens and Parriger (2010) did not contain consonant clusters. We could infer that nonword repetition skills improved in children with SLI and normal literacy as could be observed from the studies using a nonword repetition task without consonant clusters. However, we observed in our study that at least mild vSTM problems remained in children with SLI and normal literacy in comparison to typically developing children when more sensitive and complex tasks were used, such as a nonword repetition task with consonant clusters. The reason why our results for nonword repetition did still differ from those of 
Bishop et al. (2009) might have been the small difference in age and in the received literacy instruction.

We must warn that articulation errors (often apparent in children with SLI) might have an influence on nonword repetition scores, especially when clusters had to be repeated. However, articulation errors were less frequent in children in grade 3 and even after statistical correction for articulation accuracy in our study, all group differences remained.

In summary, combining our results and those of other studies, the conclusions for PA and VSTM for children with SLI were similar: children with SLI and literacy delay seemed to have persistent PA and VSTM problems on all tasks at least until grade 3, whereas children with SLI and normal literacy only showed persistent PA and vSTM problems on the more demanding tasks.

Third, we could observe that the SLI-LD group had in general lower RAN scores in kindergarten compared to the SLI-NL group and the Control-NL group, as was also mentioned in Vandewalle et al. (2010). This suggested that RAN in kindergarten might have been a good predictor for later literacy delay. With respect to the development of RAN skills, the substantial effect sizes between the two SLI groups observed in kindergarten disappeared in grade 1 and 3 . Hence, the predictive value of RAN might have decreased over the years.

A fourth conclusion dealt with the discriminative value of phonological skills in kindergarten as predictors for literacy delay in first and third grade. It appeared that a combination of PA and RAN skills discriminated relatively well between the presence versus absence of later reading and spelling problems in children with SLI. Linear discriminant analyses and cross validation on the PA and RAN composite scores resulted in a sensitivity of $75 \%$ and specificity of $80 \%$. These sensitivity and specificity were rather weak for a formal diagnosis (Plante \& Vance, 1994), but the analyses might be meaningful in highlighting the differences between the two SLI groups in kindergarten. Moreover, these might be useful as 
Development of Phonology in Children With SLI

predictors for literacy delay in kindergarten in order to start monitoring and training the children with the highest risk before the start of literacy instruction. It was not surprising that the end rime identity task and the RAN objects task resulted in the same discriminative value as the composite scores. Group comparisons revealed moderate to strong effect sizes for these tasks between both SLI groups. Both tasks were less challenging for children in kindergarten and therefore might have discriminated better between subgroups of children with SLI. A word of caution about the nature of literacy delay might be appropriate here, given that variation in literacy skills lies on a continuum rather than being clustered in two clearly distinguishable subgroups. Correlations in our previous report (Vandewalle et al., 2010) suggested that RAN but not PA scores in kindergarten were good predictors for literacy achievement in children with SLI at the end of grade 1 . The discriminant analyses of our present study however demonstrated that a combination of PA and RAN scores had the best predictive value. Only PA skills or only RAN skills did not have a similar sensitivity to detect children with SLI and literacy delay. This was in accordance with the double deficit hypothesis: PA problems, RAN problems or a combination of PA and RAN problems could cause literacy problems (Wolf \& Bowers, 1999).

Fifth, the lack of significant differences between the SLI-LD and SLI-NL groups on all but one phonological test was quite surprising. Although the effect sizes for a number of other tasks were medium to large, but not significant, one might wonder what actually might have been driving the group difference in literacy skills. In a study of Wimmer, Mayringer and Landerl (2000) it was observed that in the context of a regular orthography and a synthetic phonics teaching approach, a PA deficit had no negative influence on reading of nonwords and phonetic spelling until grade 3. However, children with a RAN deficit or a double deficit did have reading problems, more specifically reading fluency problems. In our study, the children with SLI and normal literacy tended not to have marked RAN problems 
(effect sizes between the SLI-NL group and Control-NL group for RAN were typically small to moderate) and had mild PA deficits. This might explain why these children did not experience severe literacy problems at least until grade 3 in a language with a regular orthography. It would be interesting to observe whether these children will later on develop problems with word reading, spelling and/or reading comprehension.

Sixth, two surprising phenomena regarding the reading and spelling scores should be mentioned. First, the differences between the SLI-LD group and the two normal literacy groups were not significant for all reading and spelling measures, although the groups were divided based on a combination of these scores. Possible explanations might be the lower discriminatory value of the one minute word reading test in grade 1 because of the relatively high difficulty level of the task and the fact that in a more transparent orthography children experience fewer problems with word reading at the start of reading instruction (Wimmer et al., 2000). Second, the effect sizes between the SLI-NL and Control-NL group were moderate to large for spelling scores. These differences were caused by an average score higher than the normative reference group for the Control-NL group and lower than this normative reference group for the SLI-NL group. Moreover, it is important to notice that for each task, effect sizes were larger between the SLI-LD group and the two normal literacy groups than between the SLI-NL and Control-NL group.

Finally, some limitations of the present study should be discussed. First, the sample sizes of the three groups of children were small. Therefore, group comparisons could not easily reach significance level and interpretations of group differences should have been made with caution. Second, the SLI criterion to score persistently low on only one language aspect might not have been very selective. Hence, one should be careful in generalizing our findings to a population of children with more severely impaired oral language skills. However, the whole SLI group had significantly lower scores than the control group for almost all language 
aspects in kindergarten, grade 1 and grade 3, despite the oral language therapy they all received in kindergarten (Vandewalle, Boets, Boons, Ghesquière, \& Zink, submitted; Vandewalle et al., 2010). Third, it is not clear how the oral language therapy that these children with SLI typically had for two years, might have affected our results. Fourth, the literacy criterion of $1 S D$ below the norm group might have been rather lenient, but the persistency of the reading or spelling problems was confirmed by the criterion that children had to fail on literacy in both grade 1 and grade 3. Moreover, literacy was measured relatively early and in a transparent language, so a milder criterion could be justified. However, we have to be careful in generalizing our results for children with literacy delay to the dyslexic population as we do not know which children of our study will receive the diagnosis of dyslexia later on. Fifth, within this study, we did not analyze the direction of the relations between phonology and literacy, so we could not make conclusions about their causal relationships.

Further research with a longer follow-up is needed in order to observe whether the PA and vSTM difficulties in children with SLI and normal literacy would disappear in later grades (as was observed in the study of Catts et al., 2005) or would cause permanent problems on the more demanding tasks. There is a strong need for a precise inventory of the different PA tasks with their underlying cognitive skill, their difficulty level and their role in the literacy development in typically developing children and in specific populations such as children with SLI. Based on the observation that the performance of the SLI group with normal literacy had no problems with less demanding and more familiar tasks, a training study of PA skills might be set up in kindergarten in order to detect children with SLI at risk for dyslexia at an early age. We expect that the children whose PA skills improve by this training will not develop literacy problems, while the children who show less improvement have an increased risk to develop dyslexia later on. Additionally, the development of RAN 
skills in children with SLI over a longer period and the combined predictive value of PA and RAN for the development of literacy skills are topics that need further investigation. More longitudinal studies on large groups of children with SLI with and without literacy delay in transparent and non-transparent languages starting from kindergarten are necessary to generalize the conclusions of this study to all children with SLI.

\begin{abstract}
Acknowledgments
We are grateful to Intse Boey, Liesbet Cuyvers, Ester Dewaelheyns, Ellen De Wever, Joke Lauwers, Indra Lens, Sarah Lievens, Tinne Mertens, Sarah Saey, Liesbet Schouwaerts and Tamara Van Eyken for their contribution in the data collection. We wish to acknowledge the rehabilitation centers, speech-language therapists, and the Vlaamse Vereniging voor Logopedisten $(V V L)$ [Flemish Union of Speech and Language Therapists] for assistance with the selection of the children with SLI, and all the children, their parents, schools, and teachers for their commitment to the study.
\end{abstract}


Development of Phonology in Children With SLI

\section{References}

Anthony, J. L., Lonigan, C. J., Driscoll, K., Phillips, B. M., \& Burgess, S. R. (2003). Phonological sensitivity: a quasi-parallel progression of word structure units and cognitive operations. Reading Research Quarterly, 38(4), 470-487.

Anthony, J. L., \& Lonigan, C. J. (2004). The nature of phonological awareness: converging evidence from four studies of preschool and early grade school children. Journal of Educational Psychology, 96(1), 43-55.

Anthony, J. L., \& Francis, D.J. (2005). Development of phonological awareness. Current Directions in Psychological Science, 14(5), 255-259.

Bedore, L. M., \& Leonard, L. B. (1998). Specific language impairment and grammatical morphology: a discriminant function analysis. Journal of Speech, Language, and Hearing Research, 41, 1185-1192.

Befi-Lopes, D. M., Bento, A. C. P., \& Perissinoto, J. (2008). Narration of stories by children with specific language impairment. Pró-Fono Revista de Actualização Científica, 20(2), 93-98.

Bentin, S., \& Leshem, H. (1993). On the interaction between phonological awareness and reading acquisition: it's a two-way street. Annals of Dyslexia, 43, 125-148.

Bishop, D. V. M., \& Adams, C. (1990). A prospective study of the relationship between specific language impairment, phonological disorders and reading retardation. Journal of Child Psychology and Psychiatry, 31(7), 1027-1050.

Bishop, D. V. M., \& Edmundson, A. (1987). Language-impaired 4-year-olds: distinguishing transient from persistent impairment. Journal of Speech and Hearing Disorders, 52, 156-173. 
Bishop, D. V. M., McDonald, D., Bird, S., \& Hayiou-Thomas, M. E. (2009). Children who read words accurately despite language impairment: who are they and how do they do it? Child Development, 80(2), 593-605.

Bishop, D. V. M., \& Snowling, M. J. (2004). Developmental dyslexia and specific language impairment: same or different? Psychological Bulletin, 130(6), 858-886.

Boets, B., De Smedt, B., Cleuren, L., Vandewalle, E., Wouters, J., \& Ghesquière, P. (2010). Towards a further characterization of phonological and literacy problems in Dutchspeaking children with dyslexia. British Journal of Developmental Psychology, 28, 531.

Boets, B., Wouters, J., van Wieringen, A., \& Ghesquière, P. (2006). Auditory temporal information processing in preschool children at family risk for dyslexia: relations with phonological abilities and developing literacy skills. Brain and Language, 97, 64-79.

Botting, N. (2010). 'It 's not (just) what you do, but the way that you do it': factors that determine narrative ability in atypical language learners. Developmental Medicine and Child Neurology, 52, 885-890.

Botting, N., Simkin, Z., \& Conti-Ramsden, G. (2006). Associated reading skills in children with a history of Specific Language Impairment. Reading and Writing, 19, 77-98.

Bowers, P. G. \& Ishaik, G. (2003). RAN's contribution to understanding reading disabilities. In H. L. Swanson, K. R. Harris, \& S. Graham (Eds.), Handbook of learning disabilities (pp. 140-157). New York, U.S.: Guilford Press.

Brady, S., Fowler, A., Stone, B., \& Winbury, N. (1994). Training phonological awareness: a study with inner-city kindergarten children. Annals of Dyslexia, 44(1), 26-59.

Brizzolara, D., Chilozi, A., Cipriani, P., Di Filippo, G., Gasperini, F., Mazzotti, F. et al. (2006). Do phonological and rapid automatized naming deficits differentially affect 
Development of Phonology in Children With SLI

dyslexic children with and without a history of language delay? A study of Italian dyslexic children. Cognitive and Behavioral Neurology, 19, 141-149.

Caravolas, M., \& Bruck, M. (1993). The effect of oral and written language input on children's phonological awareness: a cross-linguistic study. Journal of Experimental Child Psychology, 55(1), 1-30.

Carroll, J. M., \& Myers, J. M. (2010). Speech and language difficulties in children with and without a family history of dyslexia. Scientific Studies of Reading, 14(3), 247-265.

Catts, H. W., Adlof, S. M., Hogan, T. P., \& Weismer, S. E. (2005). Are specific language impairment and dyslexia distinct disorders? Journal of Speech, Language, and Hearing Research, 48, 1378-1396.

Catts, H. W., Gillispie, M., Leonard, L. B., Kail, R. V., \& Miller, C. A. (2002). The role of speed of processing, rapid naming, and phonological awareness in reading achievement. Journal of Learning Disabilities, 35, 510-525.

Conti-Ramsden, G., Botting, N., Simkin, Z., \& Knox, E. (2001). Follow-up of children attending infant language units: outcomes at 11 years of age. International Journal of Language and Communication Disorders, 36(2), 207-219.

Conti-Ramsden, G., \& Durkin, K. (2007). Phonological short-term memory, language and literacy: developmental relationships in early adolescence in young people with SLI. Journal of Child Psychology and Psychiatry, 48(2), 147-156.

Crais, E. R., \& Lorch, N. (1994). Oral narratives in school-age children. Topics in Language Disorders, 14(3), 13-28.

de Bree, E., Wijnen, F., \& Gerrits, E. (2010). Non-word repetition and literacy in Dutch at risk of dyslexia and children with SLI: results of the follow-up study. Dyslexia, 16(1), $36-44$. 
de Jong, P. F., Seveke, M. J., \& van Veen, M. (2000). Phonological sensitivity and the acquisition of new words in children. Journal of Experimental Child Psychology, 76(4), 275-301.

de Jong, P. F., \& van der Leij, A. (1999). Specific contributions of phonological abilities to early reading acquisition: results from a Dutch latent variable longitudinal study. Journal of Educational Psychology, 91(3), 450-476.

de Jong, P. F., \& van der Leij, A. (2003). Developmental changes in the manifestation of a phonological deficit in dyslexic children learning to read a regular orthography. Journal of Educational Psychology, 95(1), 22-40.

Dollaghan, C. A., \& Campbell, T. F. (1998). Nonword repetition and child language impairment. Journal of Speech, Language, and Hearing Research, 41, 1136-1146.

Dudal, P. (2006a). Leerlingvolgsysteem VCLB. Spelling: Toetsen 1-6. Basisboek en kopieerbundel. Leuven, Belgium: Garant.

Dudal, P. (2006b). Leerlingvolgsysteem VCLB. Spelling: toetsen 1-6. Basisboek en kopieerbundel. Leuven, Belgium: Garant.

Durgunoglu, A. Y., \& Öney, B. (1999). A cross-linguistic comparison of phonological awareness and word recognition. Reading and Writing, 11, 281-299.

Elbro, C. (1996). Early linguistic abilities and reading development: a review and a hypothesis. Reading and Writing, 8(6), 453-485.

Elbro, C. \& Scarborough, H. S. (2004). Early identification. In T. Nunes \& P. Bryant (Eds.), Handbook of children's literacy (pp. 339-359). Dordrecht, the Netherlands: Kluwer Academic.

Feagans, L., \& Appelbaum, M. I. (1986). Validation of language subtypes in learning disabled children. Journal of Educational Psychology, 78(5), 358-364. 
Fey, M. E., Catts, H. W., Proctor-Williams, K., Tomblin, J. B., \& Zhang, X. (2004). Oral and written story composition skills of children with language impairment. Journal of Speech, Language, and Hearing Research, 47, 1301-1318.

Finestack, L. H., Fey, M. E., \& Catts, H. W. (2006). Pronominal reference skills of second and fourth grade children with language impairment. Journal of Communication Disorders, 39, 232-248.

Frederickson, N., Frith, U., \& Reason, R. (1997). Phonological assessment battery: manual and test materials. Windsor, U.K.: NFER-NELSON Publishing Company Ltd.

Gathercole, S. E., Willis, C. S., Baddeley, A. D., \& Emslie, H. (1994). The children's test of nonword repetition: a test of phonological working memory. Memory, 2(2), 103-127.

Gersons-Wolfensberger, D. C. M., \& Ruijssenaars, W. A. J. J. M. (1997). Definition and treatment of dyslexia: a report by the committee on dyslexia of the Health Council of the Netherlands. Journal of Learning Disabilities, 30(2), 209-213.

Geudens, A., \& Sandra, D. (2003). Beyond implicit phonological knowledge: no support for an onset-rime structure in children's explicit phonological awareness. Journal of Memory and Language, 49, 157-182.

Gillam, R. B., \& Carlile, R. M. (1997). Oral reading and story retelling of students with specific language impairment. Language, Speech, and Hearing Services in Schools, $28,30-42$.

Gilmore, S. E., Klecan-Aker, J. S., \& Owen, W. L. (1999). The relationship of storytelling ability to reading comprehension in children with learning disability. Journal of Speech-Language Pathology and Audiology, 23(3), 142-151.

Hook, P. E. \& Haynes, C. W. (2009). Reading and writing in child language disorders. In R. G. Schwartz (Ed.), Handbook of child language disorders (pp. 424-444). New York, USA: Psychology Press. 
Jansonius-Schultheiss, K., Borgers, M., De Bruin, B. C., \& Stumpel, H. (2007). Renfrew's taalschalen Nederlandse aanpassing (RTNA): diagnostisch onderzoek en therapieopzet bij jonge taalgestoorde kinderen. Logopedie en Foniatrie, 11, 352-359.

Kit-Sum To, C., Stokes, S. F., Cheung, H.-T., \& T'sou, B. (2010). Narrative assessment for Cantonese-speaking children. Journal of Speech, Language, and Hearing Research, $53,648-669$.

Krom, R., van Berkel, S., \& Jongen, I. (2006). Begrijpend lezen groep 4: handleiding. Arnhem, the Netherlands: Cito B.V. Arnhem.

Landerl, K., \& Wimmer, H. (2000). Deficits in phoneme segmentation are not the core problem of dyslexia: evidence from German and English children. Applied Psycholinguistics, 21, 243-262.

Lerväg, A., \& Hulme, C. (2009). Rapid Automatized Naming (RAN) taps a mechanism that places constraints on the development of early reading fluency. Psychological Science, 20(8), 1040-1048.

Liles, B. Z. (1985). Cohesion in the narratives of normal and language disordered children. Journal of Speech, Language, and Hearing Research, 28, 123-133.

Liles, B. Z. (1993). Narrative discourse in children with language disorders and children with normal language: a critical review of literature. Journal of Speech and Hearing Research, 36(5), 868-882.

Liles, B. Z., Duffy, R. J., Merritt, D. D., \& Purcell, S. L. (1995). Measurement of narrative discourse ability in children with language disorders. Journal of Speech, Language, and Hearing Research, 38, 415-425.

Maillart, C., \& Schelstraete, M.-A. (2004). Phonological representations in children with SLI: a study of French. Journal of Speech, Language, and Hearing Research, 47, 187-198. 
Development of Phonology in Children With SLI

Manhardt, J., \& Rescorla, L. (2002). Oral narrative skills of late talkers at ages 8 and 9. Applied Psycholinguistics, 23, 1-21.

Marshall, C., \& van der Lely, H. (2009). Effects of word position and stress on onset cluster production: evidence from typical development, specific language impairment and dyslexia. Language, 85, 39-57.

Mayer, M. (1969). Frog, where are you? New York, U.S.: Dial Press.

McArthur, G. M., \& Bishop, D. V. M. (2001). Auditory perceptual processing in people with reading and oral language impairments: current issues and recommendations. Dyslexia, 7, 150-170.

McArthur, G. M., Hogben, J. H., Edwards, V. T., Heath, S. M., \& Mengler, E. D. (2000). On the "specifics" of specific reading disability and specific language impairment. Journal of Child Psychology and Psychiatry, 41(7), 869-874.

McArthur, G. M., Hogen, J. H., Edwards, V. T., Heath, S. M., \& Mengler, E. D. (2000). On the "specifics" of specific reading disability and specific language impairment. Journal of Child Psychology and Psychiatry, 41(7), 869-874.

Merritt, D., \& Liles, B. (1989). Narrative analysis: clinical applications of story generation and story retelling. Journal of Speech and Hearing Disorders, 54(3), 429-438.

Merritt, D. D., \& Liles, B. Z. (1987). Story grammar ability in children with and without language disorder: story generation, story retelling, and story comprehension. Journal of Speech, Language, and Hearing Research, 30, 539-552.

Muñoz, M. L., Gillam, R. B., Peña, E. D., \& Gulley-Faehnle, A. (2003). Measures of language development in fictional narratives of Latino children. Language, Speech, and Hearing Services in Schools, 34, 332-342. 
Nation, K., \& Snowling, M. J. (2004). Beyond phonological skills: broader language skills contribute to the development of reading. Journal of Research in Reading, 27, 342356.

Norbury, C. F., \& Bishop, D. V. M. (2003). Narrative skills of children with communication impairments. International Journal of Language and Communication Disorders, $38(3), 287-313$.

Pankratz, M. E., Plante, E., Vance, R., \& Insalaco, D. M. (2007). The diagnostic and predictive validity of The Renfrew Bus Story. Language, Speech, and Hearing Services in Schools, 38, 390-399.

Paul, R., Hernandez, R., Taylor, L., \& Johnson, K. (1996). Narrative development in late talkers: early school age. Journal of Speech, Language, and Hearing Research, 39, 1295-1303.

Paul, R., \& Smith, R. L. (1993). Narrative skills in 4-year-olds with normal, impaired, and late-developing language. Journal of Speech, Language, and Hearing Research, 36, $592-598$.

Pennington, B. F. (2006). From single to multiple deficit models of developmental disorders. Cognition, 101, 385-413.

Pennington, B. F., Cardoso-Martins, C., Green, P. A., \& Lefly, D. L. (2001). Comparing the phonological and the double-deficit hypotheses for developmental dyslexia. Reading and Writing, 14(7-8), 707-755.

Pennington, B. F., \& Lefly, D. L. (2001). Early reading development in children at family risk for dyslexia. Child Development, 72(3), 816-833.

Plante, E., \& Vance, R. (1994). Selection of preschool language tests: a data-based approach. Language, Speech, and Hearing Services in Schools, 25, 15-24. 
Development of Phonology in Children With SLI

Raven, J. C., Court, J. H., \& Raven, J. (1984). Manual for Raven's Progressive Matrices and Vocabulary Scales. London, UK: Lewis.

Redmond, S. M., Thompson, H. L., \& Goldstein, S. (2011). Psycholinguistic profiling differentiates specific language impairment from typical development and from attention-deficit/hyperactivity disorder. Journal of Speech, Language, and Hearing Research, 54, 99-117.

Renfrew, C. E. (1997). The Renfrew Language Scales: Bus Story Test: a test of narrative speech. (4th ed.). Bicester, U.K.: Winslow Press Limited.

Rispens, J., \& Parriger, E. (2010). Non-word repetition in Dutch-speaking children with specific language impairment with and without reading problems. British Journal of Developmental Psychology, 28, 177-188.

Scarborough, H. S. (1998). Early identification of children at risk for reading disabilities: phonological awareness and some other promising predictors. In B. K. Shapiro, P. J. Accardo, \& A. J. Capute (Eds.), Specific reading disability: a view of the spectrum (pp. 75-119). Timonium, MD, U.S.: York Press Inc.

Schaerlaekens, A., Zink, I., \& van Ommeslaeghe, K. (2003). Reynell Taalontwikkelingsschalen: Handleiding tweede versie. Lisse, the Netherlands: Swets \& Zeitlinger.

Schlichting, J. E. P. T., van Eldik, M. C. M., Spelberg, H. C. L., van der Meulen, Sj., \& van der Meulen, B. F. (2003). Schlichting Test voor Taalproductie: handleiding, derde gewijzigde druk. Lisse, the Netherlands: Swets \& Zeitlinger.

Schwartz, R. G. (2009). Specific Language Impairment. In R. G. Schwartz (Ed.), Handbook of Child Language Disorders (pp. 3-43). New York, U.S.: Psychology Press. 
Seiger-Gardner, L. (2009). Language production approaches to child language disorders. In R. G. Schwartz (Ed.), Handbook of child language disorders (pp. 465-487). New York, U.S.: Pscyhology Press.

Siegel, L. S. (2003). Basic cognitive processes and reading disabilities. In H. L. Swanson, K. R. Harris, \& S. Graham (Eds.), Handbook of learning disabilities (pp. 158-181). New York: The Guilford Press.

Snowling, M., Bishop, D. V. M., \& Stothard, S. E. (2000). Is preschool language impairment a risk factor for dyslexia in adolescence. Journal of Child Psychology and Psychiatry, 41(5), 587-600.

Snowling, M. J. (2000). Dyslexia. (2nd ed.). Oxford, UK: Blackwell Publishing Ltd.

Snowling, M. J., Gallagher, A., \& Frith, U. (2003). Family risk of dyslexia is continuous: individual differences in the precursors of reading skill. Child Development, 74(2), 358-373.

Soodla, P., \& Kikas, E. (2010). Macrostructure in the narratives of Estonian children with typical development and language impairment. Journal of Speech, Language, and Hearing Research, 53, 1321-1333.

Spear-Swerling, L. (2006). Children's reading comprehension and oral reading fluency. Reading and Writing, 19, 199-220.

Stanovich, K. E. (1988). Explaining the differences between the dyslexic and the gardenvariety poor reader: the phonological-core variable-difference model. Journal of Learning Disabilities, 21(10), 590-604.

Stothard, S. E., Snowling, M. J., Bishop, D. V. M., Chipchase, B. B., \& Kaplan, C. A. (1998). Language-impaired preschoolers: a follow-up into adolescence. Journal of Speech, Language, and Hearing Research, 41, 407-418. 
Development of Phonology in Children With SLI

Strong, C. J., \& Shaver, J. P. (1991). Stability of cohesion in the spoken narratives of language-impaired and normally developing school-aged children. Journal of Speech and Hearing Research, 34, 95-111.

Tallal, P. (1980). Auditory temporal perception, phonics, and reading disabilities in children. Brain and Language, 9, 182-198.

Thatcher, K. L. (2010). The development of phonological awareness with specific languageimpaired and typical children. Psychology in the Schools, 47(5), 467-480.

Tomblin, J. B., Records, N. L., Buckwalter, P., Zhang, X., Smith, E., \& O'Brien, M. (1997). Prevalence of specific language impairment in kindergarten children. Journal of Speech and Hearing Research, 40(6), 1245-1260.

Treiman, R., \& Zukowski, A. (1996). Children's sensitivity to syllables, onsets, rimes, and phonemes. Journal of Experimental Child Psychology, 61, 193-215.

UNESCO (1997). International Standard Classification of Education.

Uppstad, P. H., \& Tonnessen, F. E. (2007). The notion of 'phonology' in dyslexia research: cognitivism-and beyond. Dyslexia, 13, 154-174.

van Bon, W. H. J. \& Hoekstra, J. G. (1982a). Taaltest voor kinderen: Handleiding. Lisse, the Netherlands: Swets \& Zeitlinger.

van Bon, W. H. J. \& Hoekstra, J. G. (1982b). Taaltest voor kinderen: handleiding. Lisse, the Netherlands: Swets \& Zeitlinger.

van den Bos, K. P., Ruijssenaars, A. J. J. M., \& Spelberg, H. C. L. (2008). De diagnose van dyslexie en de ontwikkeling van woorden lezen. Tijdschrift voor Orthopedagogiek, 47, 325-338.

van den Bos, K. P., Spelberg, H. C. L., Scheepstra, A. J. M., \& De Vries, J. R. (1994). De Klepel. Vorm A en B. Een test voor de leesvaardigheid van pseudowoorden. 
Verantwoording, handleiding, diagnostiek en behandeling. Nijmegen, the Netherlands: Berkhout.

van den Bos, K. P., Zijlstra, B. J. H., \& Spelberg, H. C. (2002). Life-span data on continuousnaming speeds of numbers, letters, colors, and pictured objects, and word-reading speed. Scientific Studies of Reading, 6, 25-49.

Vandewalle, E., Boets, B., Boons, T., Ghesquière, P., \& Zink, I. (submitted). Oral language and narrative skills in children with specific language impairment with and without literacy delay: a three-year longitudinal study. Journal of Speech, Language, and Hearing Research.

Vandewalle, E., Boets, B., Ghesquière, P., \& Zink, I. (2010). Who is at risk for dyslexia? Phonological processing in five- to seven-year-old Dutch-speaking children with SLI. Scientific Studies of Reading, 14(1), 58-84.

Vellutino, F. R., Fletcher, J. M., Snowling, M. J., \& Scanlon, D. M. (2004). Specific reading disability (dyslexia): what have we learned in the past four decades? Journal of Child Psychology and Psychiatry, 45(1), 2-40.

Verhagen, W., Aarnoutse, C., \& van Leeuwe, J. (2008). Phonological awareness and naming speed in prediction of Dutch children's word recognition. Scientific Studies of Reading, $12(4), 301-324$.

Verhoeven, L. (1995). Drie-Minuten-Toets (DMT): handleiding. Arnhem, the Netherlands: Cito.

Verhoeven, L. \& Vermeer, A. (1986). Taaltoets Allochtone Kinderen: diagnostische toets voor de mondelinge vaardigheid Nederlands bij allochtone kinderen van 5-9 jaar (handleiding, toetsboeken, scoreboeken). Tilburg, the Netherlands: Zwijsen b.v. 
Development of Phonology in Children With SLI

Verhoeven, L. \& Vermeer, A. (2001). Taaltoets Alle Kinderen: diagnostische toets voor de mondelinge taalvaardigheid Nederlands bij kinderen van groep 1 tot en met 4 (handleiding, toetsboeken, scoreboeken). Arnhem, the Netherlands: Cito.

Wagner, R. K., \& Torgesen, J. K. (1987). The nature of phonological processing and its causal role in the acquisition of reading skills. Psychological Bulletin, 101(2), 192212.

Wagner, R. K., Torgesen, J. K., \& Rashotte, C. A. (1994). Development of reading related phonological processing abilities: new evidence of bidirectional causality from a latent variable in a longitudinal study. Developmental Psychology, 30(1), 73-87.

Walley, A. C., Smith, L. B., \& Jusczyck, P. W. (1986). The role of phonemes and syllables in the perceived similarity of speech sounds for children. Memory \& Cognition, 14(3), 220-229.

Welkowitz, J., Ewen, R. B., \& Cohen, J. (1988). Introductory statistics for the behavioral sciences. (alternate 3rd ed.). San Diego, CA, U.S.: Harcourt Brace Jovanovich.

Westerveld, M. F., \& Gillon, G. T. (2010). Oral narrative context effects on poor readers' spoken language performance: story retelling, story generation, and personal narratives. International Journal of Speech Language Pathology, 12(2), 132-141.

Westerveld, M. F., Gillon, G. T., \& Moran, C. (2008). A longitudinal investigation of oral narrative skills in children with mixed reading disability. International Journal of Speech Language Pathology, 10(3), 132-145.

Wheldall, K., \& Pogorzelski, S. (2003). Is the PhAB really fab? The utility of the Phonological Assessment Battery in predicting gains made by older low-progress readers following two terms of intensive literacy instruction. Educational Psychology, 23(5). 
Wimmer, H., Mayringer, H., \& Landerl, K. (2000). The double-deficit hypothesis and difficulties in learning to read a regular orthography. Journal of Educational Psychology, 92(4), 668-680.

Wolf, M., \& Bowers, P. (1999). The "Double-Deficit Hypothesis" for the developmental dyslexias. Journal of Educational Psychology, 91, 1-24.

Yopp, H. K. (1988). The validity and reliability of phonemic awareness tests. Reading Research Quarterly, 23(2), 159-177. 
Table 1

Characteristics of the Participants: Mean (M) and Standard Deviation (SD); Effect Size (ES)

\begin{tabular}{|c|c|c|c|c|c|c|c|c|c|}
\hline & \multirow{2}{*}{\multicolumn{2}{|c|}{$\begin{array}{c}\text { SLI-LD (1) } \\
n=8\end{array}$}} & \multirow{2}{*}{\multicolumn{2}{|c|}{$\begin{array}{c}\text { SLI-NL (2) } \\
n=10\end{array}$}} & \multirow{2}{*}{\multicolumn{2}{|c|}{$\begin{array}{c}\text { Control-NL (3) } \\
n=14 \\
\end{array}$}} & \multicolumn{3}{|c|}{ Group comparisons } \\
\hline & & & & & & & \multirow{2}{*}{$\frac{1-2}{E S}$} & \multirow{2}{*}{$\begin{array}{l}1-\mathbf{3} \\
E S\end{array}$} & \multirow{2}{*}{$\begin{array}{c}\mathbf{2 - 3} \\
E S \\
\end{array}$} \\
\hline & $M$ & $S D$ & $M$ & $S D$ & $M$ & $S D$ & & & \\
\hline \multicolumn{10}{|l|}{ KINDERGARTEN } \\
\hline Age (months) & 64.1 & 1.6 & 63.5 & 3.2 & 63.9 & 3.4 & 0.24 & 0.09 & -0.11 \\
\hline Non-verbal intelligence $^{\mathrm{a}}$ & 108.2 & 14.2 & 118.0 & 16.7 & 122.4 & 11.2 & -0.63 & -1.15 & -0.32 \\
\hline \multicolumn{10}{|l|}{ GRADE 1} \\
\hline Word reading ${ }^{\mathrm{a}, \mathrm{b}}$ & 91.3 & 7.9 & 100.5 & 6.9 & 107.9 & 15.0 & -0.79 & -0.79 & -0.37 \\
\hline Spelling ${ }^{\mathrm{a}, \mathrm{b}}$ & 74.3 & 8.8 & 92.4 & 10.3 & 100.3 & 14.0 & -1.59 & $-1.90 * *$ & -0.65 \\
\hline \multicolumn{10}{|l|}{ GRADE 3} \\
\hline Word reading ${ }^{\mathrm{a}, \mathrm{b}}$ & 78.1 & 19.3 & 102.0 & 11.8 & 107.9 & 14.4 & -1.20 & $-1.45^{*}$ & -0.36 \\
\hline Spelling ${ }^{\mathrm{a}, \mathrm{b}}$ & 67.1 & 10.7 & 92.1 & 12.6 & 107.3 & 14.5 & $-1.82 *$ & $-2.51 * * *$ & -0.86 \\
\hline
\end{tabular}


Table 2

Phonological Measures for the Three Participant Groups: Mean (M) and Standard Deviation (SD); Effect Size (ES)

\begin{tabular}{|c|c|c|c|c|c|c|c|c|c|c|c|}
\hline & \multirow[b]{3}{*}{$\alpha^{a}$} & \multirow[b]{3}{*}{$\operatorname{Max}$} & \multirow{2}{*}{\multicolumn{2}{|c|}{$\begin{array}{c}\text { SLI-LD (1) } \\
n=8\end{array}$}} & \multirow{2}{*}{\multicolumn{2}{|c|}{$\begin{array}{c}\text { SLI-NL (2) } \\
n=10\end{array}$}} & \multirow{2}{*}{\multicolumn{2}{|c|}{$\begin{array}{c}\text { Control-NL (3) } \\
n=14 \\
\end{array}$}} & \multicolumn{3}{|c|}{ Group comparisons ${ }^{b}$} \\
\hline & & & & & & & & & \multirow{2}{*}{$\begin{array}{l}\mathbf{1 - 2} \\
E S\end{array}$} & \multirow{2}{*}{$\frac{\mathbf{1 - 3}}{E S}$} & \multirow{2}{*}{$\begin{array}{r}\mathbf{2 - 3} \\
E S \\
\end{array}$} \\
\hline & & & $M$ & $S D$ & $M$ & $S D$ & $M$ & $S D$ & & & \\
\hline \multicolumn{12}{|l|}{ KINDERGARTEN } \\
\hline PA composite & & & -5.1 & 4.2 & -2.6 & 3.5 & 0.0 & 1.0 & -0.53 & $-1.67 *$ & -0.97 \\
\hline Rime production & .88 & 8 & 5.9 & 2.5 & 6.9 & 2.1 & 7.8 & 0.6 & -0.25 & -0.97 & -0.66 \\
\hline End rime identity & .69 & 12 & 6.0 & 3.7 & 9.4 & 3.0 & 10.7 & 1.3 & -0.79 & $-1.76^{*}$ & -0.76 \\
\hline First sound identity & .59 & 10 & 4.0 & 2.3 & 4.6 & 2.2 & 7.6 & 2.2 & -0.22 & $-1.44^{*}$ & $-1.23 *$ \\
\hline End sound identity & .63 & 10 & 4.0 & 3.2 & 4.2 & 2.0 & 6.1 & 2.3 & -0.25 & -0.66 & -0.51 \\
\hline vSTM composite & & & -1.8 & 1.1 & -1.7 & 0.8 & 0.0 & 1.0 & 0.31 & $-1.38^{*}$ & $-1.87 * * *$ \\
\hline Digit span & & 21 & 6.1 & 2.0 & 6.3 & 1.8 & 8.1 & 1.7 & 0.23 & -0.90 & $-1.18^{*}$ \\
\hline Nonword repetition & .84 & 48 & 10.3 & 6.1 & 11.2 & 3.2 & 22.2 & 5.9 & 0.35 & $-1.57 * *$ & $-2.21 * * *$ \\
\hline RAN composite & & & -1.67 & 1.40 & -0.42 & 0.93 & 0.00 & 1.00 & -0.79 & -1.05 & -0.30 \\
\hline Colours (items/s) & & - & 0.5 & 0.17 & 0.67 & 0.12 & 0.76 & 0.16 & -0.82 & $-1.18^{*}$ & -0.51 \\
\hline Objects (items/s) & & - & 0.51 & 0.22 & 0.68 & 0.16 & 0.72 & 0.13 & -0.70 & -0.85 & -0.09 \\
\hline \multicolumn{12}{|l|}{ GRADE 1} \\
\hline PA composite & & & -2.7 & 0.9 & -1.3 & 0.7 & 0.0 & 1.0 & -1.32 & $-2.51 * * *$ & $-1.60 * *$ \\
\hline Rime categorization & .69 & 20 & 7.1 & 4.4 & 10.5 & 4.0 & 13.3 & 3.0 & -0.48 & $-1.42^{*}$ & -0.88 \\
\hline First sound categorization & .71 & 15 & 7.3 & 2.1 & 9.1 & 1.8 & 11.5 & 3.3 & -0.89 & $-1.14^{*}$ & -0.58 \\
\hline Auditory analysis & .88 & 20 & 8.3 & 3.0 & 14.4 & 4.0 & 17.1 & 3.3 & $-1.44 *$ & $-2.75 * * *$ & -1.01 \\
\hline Auditory synthesis & .72 & 20 & 7.3 & 2.6 & 11.2 & 3.1 & 15.1 & 3.5 & -1.05 & $-2.29 * * *$ & $-1.28^{*}$ \\
\hline Phoneme deletion & .84 & 20 & 3.8 & 1.8 & 6.7 & 4.1 & 12.1 & 5.1 & -0.81 & $-2.07 * *$ & $-1.29 * *$ \\
\hline Spoonerism & .91 & 50 & 7.5 & 6.2 & 12.3 & 8.0 & 24.5 & 11.5 & -0.27 & $-1.33^{*}$ & $-1.10^{*}$ \\
\hline
\end{tabular}




\begin{tabular}{|c|c|c|c|c|c|c|c|c|c|c|c|}
\hline vSTM composite & & & -2.2 & 1.5 & -1.9 & 1.1 & $\mathbf{0 . 0}$ & 1.0 & 0.14 & $-1.56 * *$ & $-1.96 * * *$ \\
\hline Digit span & & 21 & 6.8 & 2.3 & 7.7 & 1.7 & 9.3 & 1.2 & -0.11 & -1.20 & -1.23 \\
\hline Nonword repetition & .79 & 48 & 13.9 & 4.9 & 13.0 & 4.7 & 23.5 & 5.3 & 0.54 & $-1.68 * *$ & $-2.23 * * *$ \\
\hline RAN composite & & & -0.84 & 1.20 & -0.27 & 0.83 & $\mathbf{0 . 0 0}$ & 1.00 & -0.48 & -0.50 & -0.06 \\
\hline Colours (items/s) & & - & 0.80 & 0.20 & 0.85 & 0.15 & 0.98 & 0.23 & -0.03 & -0.44 & -0.46 \\
\hline Objects (items/s) & & - & 0.74 & 0.23 & 0.89 & 0.20 & 0.90 & 0.21 & -0.69 & -0.45 & 0.25 \\
\hline Digits (items/s) & & - & 1.06 & 0.26 & 1.13 & 0.21 & 1.28 & 0.26 & -0.16 & -0.56 & -0.44 \\
\hline Letters (items/s) & & - & 1.10 & 0.36 & 1.28 & 0.26 & 1.19 & 0.26 & -0.42 & -0.15 & 0.32 \\
\hline \multicolumn{12}{|l|}{ GRADE 3} \\
\hline PA composite & & & -3.2 & 1.5 & -1.7 & 1.5 & $\mathbf{0 . 0}$ & 1.0 & -0.74 & $-2.14 * *$ & $-1.21 *$ \\
\hline Phoneme deletion & .92 & 28 & 10.3 & 7.2 & 17.5 & 7.1 & 23.1 & 4.0 & -0.84 & $-2.09 * *$ & -0.95 \\
\hline Spoonerism & .92 & 50 & 16.9 & 10.1 & 24.0 & 10.3 & 37.9 & 8.4 & -0.44 & $-1.78^{* *}$ & $-1.25 *$ \\
\hline vSTM composite & & & -2.0 & 1.4 & -1.2 & 1.1 & 0.0 & 1.0 & -0.33 & $-1.36 *$ & -1.10 \\
\hline Digit span & & 21 & 8.6 & 2.4 & 9.5 & 1.4 & 10.2 & 1.3 & -0.17 & -0.59 & -0.53 \\
\hline Nonword repetition & .79 & 48 & 17.6 & 4.4 & 21.2 & 5.4 & 28.5 & 4.7 & -0.49 & $-2.09 * *$ & $-1.44 * *$ \\
\hline RAN composite & & & -2.02 & 1.50 & -1.08 & 1.30 & 0.00 & 1.00 & -0.48 & $-1.40 *$ & -0.88 \\
\hline Colours (items/s) & & - & 0.86 & 0.20 & 0.99 & 0.15 & 1.16 & 0.18 & -0.55 & $-1.46^{*}$ & -1.08 \\
\hline Objects (items/s) & & - & 0.84 & 0.20 & 0.95 & 0.22 & 1.06 & 0.12 & -0.36 & -1.02 & -0.50 \\
\hline Digits (items/s) & & - & 1.42 & 0.33 & 1.60 & 0.36 & 1.81 & 0.19 & -0.31 & -1.19 & -0.69 \\
\hline Letters (items/s) & & - & 1.29 & 0.39 & 1.49 & 1.17 & 1.71 & 0.38 & -0.58 & -0.99 & -0.69 \\
\hline
\end{tabular}

Note. ${ }^{\mathrm{a} C r o n b a c h}$ 's $\alpha ;{ }^{b} \mathrm{MMA}$ with maternal educational level as covariate; ${ }^{*} \mathrm{p}<.05,{ }^{* *} \mathrm{p}<.01,{ }^{* * *} \mathrm{p}<.001$ 
Table 3

Percentages and Total Number of Children with SLI Correctly Classified in the Cross-

Validation Analyses Into a Group of Children with Delayed Versus Normal Literacy Delay Based on Phonological Composite Scores in Kindergarten.

\begin{tabular}{lcc}
\hline & SLI and literacy delay & SLI and normal literacy \\
& $\boldsymbol{n}=\mathbf{8}$ & $\boldsymbol{n}=\mathbf{1 0}$ \\
\hline PA + vSTM + RAN & $75 \%$ & $80 \%$ \\
PA + vSTM & $38 \%$ & $70 \%$ \\
PA + RAN & $75 \%$ & $80 \%$ \\
vSTM + RAN & $63 \%$ & $90 \%$ \\
PA & $63 \%$ & $80 \%$ \\
vSTM & $25 \%$ & $30 \%$ \\
RAN & $63 \%$ & $80 \%$ \\
\hline
\end{tabular}

